\title{
The Measure and Control of Enterprise
}

\section{Marketing Risk in the E-business Environment}

\author{
Lingbing Hu, Baoyin Zhang, Yu Wu \\ School of Management, Tianjin University, Tianjin 300072, China
}

\begin{abstract}
In this article, through analyzing the change of enterprise marketing mode and the characters of marketing risk in the e-business environment, we establish the 3D embedded random measure model which suits for the e-business enterprise marketing risk, define the combination rules of the risk index system of this model, establish the theoretical base to measure the marketing risk for e-business enterprises, and analyze the warning and control of enterprise marketing risk under the model.
\end{abstract}

Keywords: E-business, Marketing risk management, 3D embedded random measure model, Warning and control

As a relative new research direction in the marketing management domain, the marketing risk management has been obtained fully attentions in foreign and domestic market. However, the research to the marketing risk management in foreign and domestic academe still mainly stays on the layer of qualitative analysis to general risk management, and the integrated system research combining qualitative analysis with quantitative analysis still lacks. Furthermore, with the quick development and extensive application of information technology, e-business occurs. As sort of new marketing mode and business operation mode, it fully changes the traditional marketing mode by virtue of the information technology, and it increases the marketing risk of enterprise when it brings advantages and efficiencies to enterprise marketing and management (E-Commerce Risk Management, 2001).

\section{The change and marketing risk of enterprise marketing mode in the e-business environment}

\subsection{The change of enterprise marketing mode in the e-business environment}

As the electric trading market, e-business will exert very important function in future trading activities for enterprises. It is not only a sort of electric network form of enterprise marketing management activity, but also the comprehensive strategy which redefines traditional business activity model and maximizes client values and enterprise profits by virtue of the information technology. In the e-business environment, large differences exists between enterprise marketing activities with traditional marketing activities for the ideas, which mainly are represented in (1) from large scaled and popular marketing to popular customized marketing, i.e. one to one marketing, (2) from single marketing to mutual marketing, (3) the marketing management develops from disperse and independent process to uniform and cooperate full-process marketing. Again, as viewed from the marketing mode, in the e-business environment, the enterprise marketing needs implementing in real market and network market at the same time. This change of marketing activity will bring large uncertainties to the management and taking for enterprises, i.e. the enterprise marketing risk in the e-business environment.

\subsection{The characters of enterprise marketing risk in the e-business environment}

The concept of risk is very important to e-business enterprises, and many researches which take rational decision-making as base thought that the decision-making of purchase is based on the cost benefit analysis of risk adjustment, so the risk plays the important role in the e-business activities of enterprises, and the sources of risk can be divided into enterprise exterior risk and enterprise interior risk. However, the risk researches to e-business enterprise always stay in the technical layer or the credit layer, and considering that the e-business changes litter to the traditional management mode, the character that the e-business is the generalized enterprise marketing mode has not deserved necessary recognition. To establish the model that can analyze the marketing risk for e-business enterprise, according the enterprise marketing mode in the e-business environment, we first analyze the characters of enterprise marketing in the e-business environment.

\subsubsection{The character of magnification}

Because the information communication among marketing bodies is more direct and effective, the obstacle of space has been spanned, and the negative information spread of marketing is more extensive and convenient which would bring large loss and serious results, so the network marketing in the e-business environment can amplify the risk in the real market for enterprises and induce the enterprises which are not familiar with e-business underestimate the marketing risks facing by them. 


\subsubsection{The character of diversity}

Because enterprise would face two markets including the network market and the real market in the e-business environment and possesses diversiform interior and exterior participation bodies, and the operation platform of e-business needs the diversity of management technology and information technology, so the sources of marketing risk will present the character of diversity in the e-business environment.

\subsubsection{The character of process}

The marketing activity of enterprises in the e-business environment needs the information flow, the logistical flow and the capital flow harmonize in time and space, and the implementation of every phase would company with the production of risks with difference characters, so the marketing risk in the e-business environment possess lively character of process.

\subsubsection{The character of layer}

As a sort of information system platform, the e-business mode possess the character of layer whether for the system structure of the platform or for the decision process of the marketing, and the marketing risk produced in every layer would bring different losses, and the decision-making risk always exceeds the occupational risk.

\subsubsection{The character of technology}

Comparing with traditional marketing mode, the enterprise marketing activity in the e-business environment more depends on the advancement of technology. First, the network security information technology is needed, because the network security technology problem will bring large losses for enterprise. Second, the exterior technical advancement would quickly influence the production distribution of enterprises through the network. And enterprises will suffer large losses if they turn a blind eye to these technical changes.

\subsubsection{The character of uncertainty}

Because the operation of e-business platform needs not only technical support but also the participation of the management layer, so the marketing activity in the e-business platform is a sort of non-structured systematic behavior, and under this mode, the enterprise marketing activity will face the risk with large character of uncertainty.

To help e-business enterprises better management the risk of marketing, we will establish the enterprise marketing risk random measure model in the e-business environment according to the characters of enterprise marketing risk in the e-business environment, and systematically and comprehensively identify, evaluate, warn and control the marketing risk for the e-business enterprises.

\section{The identification and measure model of e-business enterprise marketing risk}

\subsection{The $3 d$ embedded random measure model of e-business enterprise marketing risk}

According to the general process of the risk management and the characters of enterprise marketing risk in the e-business environment, we adopt a 3D identification model to conform the risk factors in the phase of risk identification, adopt a 3D random measure model to measure the risk situation in the phase of risk evaluation, and establish the 3D embedded random measure model based on the above two models, and the basic structure of the model is seen in Figure 1.

This model includes two 3D models. The first 3D identification model is mainly used in the identification to the e-business enterprise marketing risk, and implements the qualitative risk identification and conform the risk sources and risk factors of the e-business enterprises and primarily judge the importance to these risk factors. The three coordinates of the model are composed by layer, flow and factor. When implementing risk identification, the layer dimension confirms the risk resources on the interior management space and exterior environment, mainly emphasizes the environment factors on different layers and the people on the posts in different layers, and generally, the management layer can be divided into the decision-making layer, the occupational layer and the operation layer, and the object is the group corporation, many fractal structured decision layer, occupational layer and operational layer may exist, and the layer of the environment can be divided into macro environment, industrial environment, and regional industrial environment, and lower environmental layer effects the enterprise marketing risk more directly. The flow dimension confirms the logic stage of risk from the logical sequence, and it mainly emphasizes the design factor of enterprise e-business activity operation flow when identifying the risk, and according to the character of the flow, it can be divided into the plan flow, the implementation flow and the control flow, and according to the main bodies involved by the flow, it can be divided into exterior flow and interior flow, and according to the objects involved by the flow, it can be divided into information flow, capital flow, human flow and material flow. The factor dimension confirms the risk sources from the view of risk factor and emphasizes the exterior environment factor and the interior resource factor of risk identification, and it can be divided into the 
equipment resource, the technology resource, the knowledge resource, the information resource, the immaterial resource and the client resource.

Through various flows on the different management layers, or the factors analysis involved in the integrated flow on different management layers, we can confirm the risk source and the risk factor and establish bases for the risk identification.

The second model is mainly used in the evaluation of risk factor. Being different with the first 3D identification model, this model mainly solves the risk measure problem of e-business enterprise through quantitative computation. The traditional risk measure is computed by two factors including the probability which is used to estimate the possibility of risk occurrence and the price which is the cost paid by enterprises because of the occurrence of risk or the prevention of risk, and it measures the risk through confirming the probability and the price, i.e. $\mathrm{R}=$ Pro.Pri. However, this traditional risk measure method lacks the consideration of preference to risk assumption personnel or enterprise risk and can not completely reflect the essential meaning of the risk. To objectively measure the risk, we add the measure of ability, will and confidence of the risk assumption when the main body of risk assumption faces risk, i.e. the preference. These three indexes can completely measure the risk of enterprises, and we can find a sort balance relationship among them, and under the condition of balance, any two factors will automatically decide the third factor. For example, the price and probability are confirmed, we can deduce the preference, or the price and the preference are confirmed, we can confirm the probability. Through the present risk management practice only pay more attention to one of them or two of them, but this mutual function indicates that these three factors depend on each other. This dependent relationship can be described through the following definition.

\subsection{The combination index system of e-business enterprise marketing risk}

Definition 1: Supposed that the e-business enterprise marketing risk is a risk system $\mathrm{S}$ which aims are to reduce losses and actualize the increment of the enterprise, and $\mathrm{S}$ is the space composed by $3 \mathrm{D}$ vector layer $a$, flow $b$ and factor $c$. And one e-business trading that enterprise completes once is a random course $X(t, S)$, and the implementation of this event depends on the realization of 3D vector, and supposed that the $3 \mathrm{D}$ vectors in the enterprise system $S$ can be listed and added, i.e.

(1) $a, b$ and $c$ are incompatible and can not be replaced mutually, which can be presented as $a b c=\Phi$ (empty set) and $a \cup b \cup c=\Omega$ (full set).

(2) The factors contained in every $a, b$ and $c$ are incompatible and can not be replaced mutually, i.e. $a_{1} a_{2} \Lambda a_{m}=\Phi$ ( $a_{i} \in a$ is the layer factor), $a_{1} \cup a_{2} \Lambda \cup a_{m}=\Omega$, and the other two dimensions are same with this one.

So the phase risk of the system in the $\mathrm{i}$ phase when e-business enterprises trade can be defined as $R\left(X\left(t=i, a_{i} \cup b_{i} \cup c_{i}\right)\right)=R\left(a_{i}\right) \cup R\left(b_{i}\right) \cup R\left(c_{i}\right)=R\left(a_{i}\right)+R\left(b_{i}\right)+R\left(c_{i}\right)$. Through the analysis of layer, flow and factor, we can find the set of various factors involved in the e-business trading process, and we can analyze the index risk of single factor to various factors, and the computation of single factor index risk can be implemented through Definition 2.

Definition 2 (single factor index risk combination index): Supposed that the invalidation probability of the risk factor $y_{i}\left(y_{i} \in \Omega\right)$ is $\operatorname{Pr} o_{i}$, and the enterprise payment price when enterprises fail to prevent factor invalidation or the factor is invalidated is $\operatorname{Pr} i_{i}$, and here, the enterprise assumption ability or will preference to factor invalidation is $\operatorname{Pr} e_{i}$, so the risk combination index of the factor $y_{i}$ can be defined as $R\left(y_{i}\right)=f_{i}\left(\left\|\operatorname{Pr} e_{i}-\operatorname{Pr} o_{i} \times \operatorname{Pr} i_{i}\right\|\right)$. Where, $\|\bullet\|$ presents the Euclidian space distance and $f_{i}(\bullet)$ presents the mapping of $R^{+} \rightarrow R$.

To the risk judgment of the single factor index $y_{i}$, we can measure the risk according to the character of the function $R\left(y_{i}\right)$ value. Supposed that the relationship that the mapping $f_{i}(\bullet)$ describes is $R\left(y_{i}\right)=\operatorname{Pr} e_{i}-\operatorname{Pr} o_{i} \times \operatorname{Pr} i_{i}$, and when $R\left(y_{i}\right)=0$, the risk induced by the factor $y_{i}$ equals to the risk of preference that the enterprise favors this factor, so it is in the status of balance, and the risk of this factor can be accepted by the enterprise, and when $R\left(y_{i}\right)>0$, the risk induced by the factor $y_{i}$ is smaller than the risk of preference that the enterprise favors this factor, and when $R\left(y_{i}\right)<0$, the risk induced by the factor $y_{i}$ exceeds the risk of preference that the enterprise favors this factor, and in these two situations, the risk acceptance degree of the factor can be adjudged by certain warning mechanism. The risk combination index of single factor index locally reflects the balance situation of e-business enterprise marketing risk, and it can not completely reflect the making risk status faced by the enterprise, so in order to comprehensively reflect the marketing risk when the enterprise completes once e-business trading, we need to combine the risk index of single factor index. According to Definition 1, when e-business enterprises trade, 28 
the risk index in the $\mathrm{i}$ phase can be combined as the sum of single risk index, and to make this combination rules more reasonable and reflect the importance degrees of various factors, we should consider the weight factor when combining the index in the phase risk, in the process risk of the whole trading process and the comprehensive marketing risk of e-business enterprises.

Definition 3 (phase risk combination index): Supposed the risk factor set in the $\mathrm{j}$ phase is

$Y_{j}=\left\{y_{i} \mid i=1,2, \Lambda, m, y_{i} \in \Omega\right\}(j=1,2, \Lambda n)$.

The risk index of $y_{i}$ is combined according to Definition 1, so the phase risk combination index $R\left(Y_{j}\right)$ in the $\mathrm{j}$ phase is

$R\left(Y_{j}\right)=\sum_{i=1}^{m} \alpha_{i} R\left(y_{i}\right)$.

Where, $\alpha_{i}$ is the risk index weight of the risk factor $y_{i}$.

Similarly with Definition 3, we can define the process risk combination index $R\left(X_{k}\right)(k=1,2, \Lambda o)$ in certain trading process $\mathrm{k}$ and the e-business comprehensive risk combination index $R(S)$ as

$$
\begin{aligned}
& R\left(X_{k}\right)=\sum_{j=1}^{n} \beta_{j} R\left(Y_{j}\right)=\sum_{j=1}^{n} \sum_{i=1}^{m} \alpha_{i} \beta_{j} R\left(y_{i}\right) \\
& R(S)=\sum_{k=1}^{o} \gamma_{k} R\left(X_{k}\right)=\sum_{k=1}^{o} \sum_{j=1}^{n} \sum_{i=1}^{m} \alpha_{i} \beta_{j} \gamma_{k} R\left(y_{i}\right)
\end{aligned}
$$

Similarly with the judgment of single factor index risk, the balance judgments of phase risk, process risk and comprehensive risk can refer to the judgment method of single factor risk.

\section{The warning and control of enterprise marketing risk in the e-business environment}

Through the risk identification and evaluation of e-business enterprise, we can compute the risk measure that the evaluation needs, and next work is the warning and control of risk. In the phase of risk warning, we need adopting two steps, and one is to analyze the balance status of three factors of risk according to the measure of single factor risk, and judge the risk acceptance degree of single factor index according to established balance conditions, and complete the risk warning to single factor index. And the second one is to compute the comprehensive risk index according to the risk measure value of single factor index and the above combination model of risk index (Definition 3), and judge the comprehensive risk acceptance degree of enterprises according the standard of comprehensive risk index.

The key part in the phase of risk control is to find key influencing factors through auditing and evaluating relative risk factors, and make enterprises spend minimum price investment and obtain the most effective risk control effect. According to anterior analysis, because the price investment of enterprises in the risk control will influence the occurrence probability of the risk and the risk preference of enterprises and induce the corresponding changes of enterprise comprehensive risk status, so the real time in the phase of risk control is the key to obtain the success of the risk control.

\section{Conclusions}

In this article, through analyzing the change of enterprise marketing mode and the characters of marketing risk in the e-business environment, we establish the $3 \mathrm{D}$ embedded random measure model which suits for the e-business enterprise marketing risk, define the combination rules of the risk index system of this model, and establish the theoretical base to measure the marketing risk for e-business enterprises.

Furthermore, through the example that this model is applied in the e-business marketing risk management practice in certain corporation, the model is recognized by all management personnel in the corporation and achieves good effects, and it not only optimizes the risk management flow of the corporation, but also reduce the cost of risk control and enhance the efficiency of risk management.

The problems needing to be further researched include the 3D measure mathematical statistical analysis of single factor risk index, the segment layer research of 3D identification model and the application and implementation program of this model in the e-business marketing risk management.

\section{References}

David Fishbaum. (2001). Quantifying E-Commerce Risk. CAS Seminar on Ratemaking.

E-Commerce Risk Management. (2001). AFP200021st Annual Conference. Nov. 2000. 
Liwei. (2002). Theoretical Study of Early-warning Index System on Marketing Safety of Industry Enterprise. China Industrial Economics. No.8. p.87-93.

Pierre Giot, Laurent. (2003). Market Risk in Commodity Markets: a VaR Approach. Energy Economics. No.25(5). p.435-457.

Shelian, Gao, Fengyan \& Li, Dongjiu. (1999). Enterprise Marketing Warning Management. Shijiazhuang: Hebei Science and Technology Press.

Xueyuan Wu, Kam C. Yuen. (2003). A Discrete-time Risk Model with Interaction between Classes of Business. Insurance: Mathematics and Economics. No.33. p.117-133.

Yuanfeng \& Sukai. (2004). Research on Risk Preventing System for EC Enterprises. Logistics Sci-tech. No.6(6). p.49-52.

Zhang, Yunqi. (2000). Marketing Risk Rank Evaluation and Warning Control. Chinese Journal of Management Science. No.8(11). p.347-355.

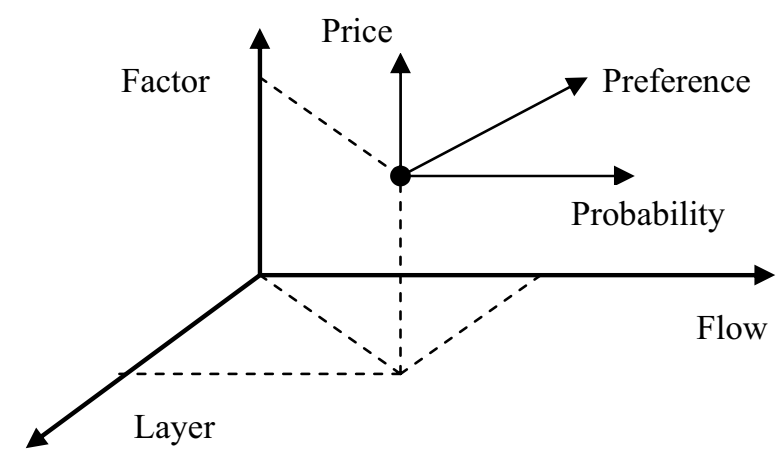

Figure 1. 3D Embedded Random Measure Model of Marketing Risk 